\title{
Assessing the impact of climate variability on catchment water balance and vegetation cover
}

\author{
X. Xu' ${ }^{1}$, D. Yang ${ }^{1}$, and M. Sivapalan ${ }^{2,3,4}$ \\ ${ }^{1}$ State Key Laboratory of Hydroscience and Engineering, Department of Hydraulic Engineering, Tsinghua University, \\ Beijing, 10084, China \\ ${ }^{2}$ Department of Civil and Environmental Engineering, University of Illinois at Urbana-Champaign, Urbana, IL 61801, USA \\ ${ }^{3}$ Department of Geography, University of Illinois at Urbana-Champaign, Urbana, IL 61801, USA \\ ${ }^{4}$ Department of Water Management, Faculty of Civil Engineering and Geosciences, Delft University of Technology, \\ Postbus 1048, Stevinweg 1, 2600 GA Delft, The Netherlands
}

Correspondence to: D. Yang (yangdw@mail.thu.edu.cn)

Received: 13 June 2011 - Published in Hydrol. Earth Syst. Sci. Discuss.: 29 June 2011

Revised: 4 December 2011 - Accepted: 10 December 2011 - Published: 6 January 2012

\begin{abstract}
Understanding the interactions among climate, vegetation cover and the water cycle lies at the heart of the study of watershed ecohydrology. Recently, considerable attention is being paid to the effect of climate variability on catchment water balance and also associated vegetation cover. In this paper, we investigate the general pattern of long-term water balance and vegetation cover (as reflected by fPAR) among 193 study catchments in Australia through statistical analysis. We then employ the elasticity analysis approach for quantifying the effects of climate variability on hydrologic partitioning (including total, surface and subsurface runoff) and on vegetation cover (including total, woody and non-woody vegetation cover). Based on the results of statistical analysis, we conclude that annual runoff $(R)$, evapotranspiration $(E)$ and runoff coefficient $(R / P)$ increase with vegetation cover for catchments in which woody vegetation is dominant and annual precipitation is relatively high. Control of water available on annual evapotranspiration in non-woody dominated catchments is relatively stronger compared to woody dominated ones. The ratio of subsurface runoff to total runoff $\left(R_{g} / R\right)$ also increases with woody vegetation cover. Through the elasticity analysis of catchment runoff, it is shown that precipitation $(P)$ in current year is the most important factor affecting the change in annual total runoff $(R)$, surface runoff $\left(R_{\mathrm{S}}\right)$ and subsurface runoff $\left(R_{g}\right)$. The significance of other controlling factors is in the order of annual precipitation in previous years $\left(P_{-1}\right.$ and $P_{-2}$ ), which represents the net effect of soil moisture
\end{abstract}

and annual mean temperature $(T)$ in current year. Change of $P$ by $+1 \%$ causes a $+3.35 \%$ change of $R$, a $+3.47 \%$ change of $R_{\mathrm{S}}$ and a $+2.89 \%$ change of $R_{g}$, on average. Results of elasticity analysis on the maximum monthly vegetation cover indicate that incoming shortwave radiation during the growing season $\left(R_{\text {sd,grow }}\right)$ is the most important factor affecting the change in vegetation cover. Change of $R_{\mathrm{sd} \text {,grow }}$ by $+1 \%$ produces a $-1.08 \%$ change of total vegetation cover $\left(F_{\mathrm{t}}\right)$ on average. The significance of other causative factors is in the order of precipitation during growing season, mean temperature during growing season and precipitation during nongrowing season. Growing season precipitation is more significant than non-growing season precipitation to non-woody vegetation cover, but both have equivalent effects to woody vegetation cover.

\section{Introduction}

Understanding the interactions among climate, vegetation and water balance in water-limited regions is one of the most widely studied subjects in watershed ecohydrology. Water supply (precipitation) and demand (potential evapotranspiration) are major factors affecting long-term water balance (Budyko, 1974; Milly, 1994). Runoff and its components are controlled by both climatic factors and landscape properties (Horton, 1933). The climatic factors (such as precipitation, radiation and temperature) are also key determinants for 
the distribution (Stephenson, 1990) and productivity (Churkina et al., 1999; Huxman et al., 2004) of vegetation around the world. The spatial pattern of vegetation cover is known to naturally arise in response to water availability (Caylor et al., 2005). The total woody vegetation cover has been found to saturate to $100 \%$ at precipitation values of $600-$ $1000 \mathrm{~mm}$ across African savannah ecosystems (Sankaran et al., 2005). Projected changes in climate will undoubtedly alter the runoff regime (Barnett et al., 2005) and extremes (Milly et al., 2002; Dai et al., 2004) as well as vegetation productivity (Knapp et al., 2001). Since the growth of vegetation is affected by intermittence of water availability (Baudena et al., 2007), any spatial and temporal change in precipitation can be expected to exert a significant influence on variability of vegetation cover. In recent times, hydrologists have paid considerable attention to how much of the observed change in water balance components (runoff and its components) and vegetation cover (woody and non-woody) can be attributed to the climate variability.

The sensitivity of annual runoff to changes in temperature and precipitation has been investigated empirically as well as theoretically (Arnell, 1996). Revelle and Waggoner (1983) used multivariate statistical analysis to estimate the relationship between changes in climate and runoff. Another common approach is to use deterministic watershed hydrologic models, by varying the models' meteorological inputs and estimating the resulting changes in runoff. Schaake (1990) proposed a simple climate elasticity model to evaluate the effect of climate changes on runoff based on the use of observed precipitation and runoff data. Vogel et al. (1999) used a regional multivariate regression model to show that a $10 \%$ increase in precipitation should lead to a $19 \%$ increase in annual runoff for the entire upper Colorado River. Sankarasubramanian et al. (2001) derived runoff elasticity to precipitation change analytically using the Turc-Pike equation based on the Budyko hypothesis. Ma et al. (2010) used a physically-based distributed hydrological model to quantify the contribution of climate variability to the decrease in river runoff. However, the use of hydrological models suffers from the uncertainty associated with model calibration and the runoff sensitivity to climate change derived from such hydrological models is limited in light of large quantities of data for catchment studies. Application of a two parameter elasticity model to the Miyun Reservoir catchment showed that both the precipitation and air temperature variation significantly impacted the streamflow elasticity (Ma et al., 2010).

Most current research in this area is limited to the analysis of total runoff, but the contributions of surface runoff and subsurface runoff are usually determined by models that can simulate within-year runoff variability. Harman et al. (2011) used a functional water balance model proposed by Ponce and Shetty (1995) to quantify the sensitivity of runoff components to the inter-annual variation of precipitation in MOPEX catchments located within continental United States and determined which of the functional parameters plays the most important role in determining the elasticity of the runoff components to precipitation variability. Yokoo et al. (2008) found that a switch from subsurface stormflow to surface runoff dominance occurs under a unique combination of soil type and topographic slope, which itself is affected by the relative seasonality of precipitation and potential evapotranspiration. Merz et al. (2009) found that surface runoff did not differ significantly between herb- and grass-dominated plots but vegetation cover change had a significant effect on surface runoff in the test plots under different land-use intensities.

How the variability of vegetation cover is related to climate in a catchment or a region is a question that has intrigued both hydrologists and ecologists (Rosenzweig, 1968; Knapp et al., 2001). Most previous studies have used ecohydrology models to investigate the effect of climate variability on vegetation cover. Eagleson $(1978,2002)$ investigated the influence of climate-soil-vegetation interactions on annual water balance. Kochendorfer et al. (2010) proposed several enhancements and modifications to Eagleson's model through improving its physical realism at the expense of its mathematical elegance and analytical tractability. They concluded that their Statistical-Dynamical Ecohydrology Model (SDEM) does provide a new framework for studying the controls of soil texture and climate on vegetation density and evapotranspiration. Using a dynamic vegetation model, $\mathrm{Ni}$ et al. (2006) determined that variability in the temperature of the coldest month can induce evergreen mortality.

Woody and non-woody vegetation have unique advantages and disadvantages when competing for variable resources of water, nutrients, and light (Notaro, 2008). Plot-scale studies have suggested that woody or forest vegetation is less sensitive to drought than grasslands (Scott et al., 2006). Due to their shallow roots, grasses are highly responsive to interannual precipitation fluctuations (Schlesinger, 1997; Knapp et al., 2002). The grass growth is dependent on upper-soil water resources (Scanlon et al., 2005), so increased precipitation variability results in reduced grass growth in grasslands (Knapp et al., 2002) and drylands (Williams and Albertson, 2006). Most forests usually have sufficient moisture to meet evapotranspiration demands and growth even during years with below-average precipitation (Knapp et al., 2002) due to deep roots. Previous studies of climate variability impacts on vegetation have been regionally focused and vastly differ in their conclusions. Higher precipitation variability favors tree establishment, e.g. in Argentina's ecotones (Grau and Veblen, 2000). However, Ni et al. (2006) showed that an increase in precipitation variability in China and in North Africa favored grasses over trees.

Most previous studies cited above focused on the effect of climate variability on catchment water balance, especially on runoff. In addition, some studies have also explored the effects of climate variability on runoff components, such as surface and subsurface runoff. In this paper we extend this analysis to include the effects on vegetation cover using a simple elasticity model to assess the impact of climate 
variability on both catchment water balance and vegetation cover. Due to data limitations, most previous data-based studies have typically ignored the effect of inter-annual variability (i.e. carry-over) of soil moisture storage on annual water balance. The antecedent precipitation (precipitation in previous years for runoff and its components or precipitation during non-growing season for vegetation cover) is introduced in this paper to reflect the changes of soil moisture storage (both within and between years). The objectives of this paper are: (1) to explore the general pattern of long-term water balance and vegetation cover over broad climate regions; (2) to quantify the effects of climate variability on runoff and water balance; and (3) to quantify the effects of climate variability on vegetation cover. We accomplish this using water balance and vegetation cover data from 193 catchments in Australia. This is an extension of the work carried out by Harman et al. (2011) on a large number of US catchments.

\section{Study area and data}

By overlapping available datasets of climate, hydrology and vegetation from 1981 to 2006 across Australia, we selected 193 catchments as study catchments containing at least 10 years of complete records whose dryness index values (the ratio of mean annual potential evapotranspiration to precipitation, $E_{0} / P$ ) span a wide range from 1.0 to 4.69 . The catchments are unimpaired and were collated for an Australian Land and Water Resources Audit project (Peel et al., 2000). "Unimpaired" catchments refer to catchments draining to/from unregulated rivers and/or where regulation changed the natural monthly streamflow volumes by less than $5 \%$. Therefore, there are not much human activities in the study areas. Most of the catchments are located in the east and south-east of Australia (see Fig. 1). The drainage areas of the study catchments range from $51-1937 \mathrm{~km}^{2}$.

Long-term monthly discharge and precipitation data used in this study are described in Donohue et al. (2010) and daily streamflow data is collected from National Land and Water Resources Audit dataset (Peel et al., 2000). The monthly data have complete records from 1981 to 2006, but the daily discharge data that can be used to separate baseflow from total runoff are only available up to 1998. Based on the annual water balance equation, actual annual evapotranspiration is calculated by ignoring inter-annual variability of catchment water storage. The potential evapotranspiration is estimated using the Penman equation (Donohue et al., 2010), using the available catchment datasets. Monthly incoming shortwave radiation data are available from the Bureau of Meteorology's Australian Water Availability Project datasets (Donohue et al., 2010, also in http://www-data.wron.csiro. $\mathrm{au} /$ ). Monthly temperature data are obtained from Jones et al. (2009).

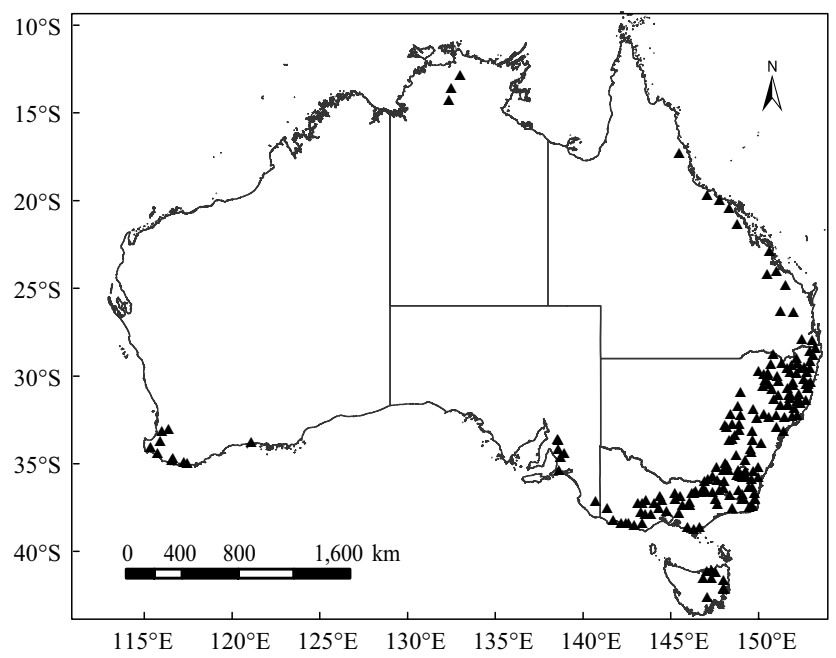

Fig. 1. Distribution of the 193 study catchments (the triangle placed in the outlet of each catchment).

As demonstrated by Troch et al. (2009), the estimation of annual water balance metrics was not highly sensitive to the baseflow separation method. So we use a one-parameter lowpass filter algorithm developed by Lyne and Hollick (1979) to separate the daily runoff $(R)$ into surface runoff $\left(R_{\mathrm{S}}\right)$ and subsurface runoff $\left(R_{g}\right)$ as:

$R_{g}^{k}=a R_{g}^{k-1}+\frac{1-a}{2}\left(R^{k}+R^{k-1}\right)$

$R_{g}^{k} \leq R^{k}$

in which $k$ is the time step number, the value of the single filter parameter $a$ is 0.925 for all catchments, following the suggestions by Arnold and Allen (1999) and Eckhardt (2005). Mean annual ratio of subsurface runoff to total runoff $\left(R_{g} / R\right)$ range is from 0.18 to 0.84 , with an average of 0.54 in the 193 study catchments.

The percent green cover is estimated from the fraction of absorbed photosynthetically active radiation (fPAR) (Donohue et al., 2009), which is estimated from remote sensing data. Therefore, we use fPAR to represent vegetation cover in this paper. The fPAR data are obtained from an Australian AVHRR-derived monthly fPAR dataset (Donohue et al., 2008), and are available for the period from July 1981 to December 2006, with a spatial resolution of $0.01^{\circ}$. The monthly values of total fPAR are averaged to estimate the annual mean. The dynamics of perennial and annual vegetation functional types can be approximated by splitting total fPAR into its constituent persistent and recurrent components using the method presented by Donohue et al. (2009, 2010). Persistent fPAR $\left(F_{\mathrm{p}}\right)$ represents the cover from perennial, non-deciduous vegetation types; recurrent fPAR $\left(F_{\mathrm{r}}\right)$ represents that from annual, ephemeral and deciduous vegetation. For Australian landscapes, these two components 
approximately represent woody and non-woody vegetation types, respectively (Donohue et al., 2009; Gill et al., 2009). Figure 2 presents an example of mean monthly total fPAR $\left(F_{\mathrm{t}}\right)$, persistent fPAR $\left(F_{\mathrm{p}}\right)$ and recurrent fPAR $\left(F_{\mathrm{r}}\right)$ as a function of calendar month. As expected, the persistent fPAR is relatively constant over the year, whereas recurrent fPAR (and consequently the total fPAR) exhibits a strong seasonal variation.

\section{Methodology}

The general pattern of long-term water balance and vegetation cover is investigated in a qualitative way using correlation analysis. The impact of inter-annual variability of climate on annual runoff and vegetation cover is then assessed in a quantitative way using elasticity models.

\subsection{Correlation analysis}

Correlation analysis was used to explore the general pattern among climate, long-term water balance and vegetation cover in the study catchments. Relationship between any two variables is detected by linear correlation analysis. The mathematical formula for computing the linear correlation coefficient $(\rho)$ is:

$\rho=\frac{n \sum x y-\left(\sum x\right)\left(\sum y\right)}{\sqrt{n\left(\sum x^{2}\right)-\left(\sum x\right)^{2}} \sqrt{n\left(\sum y^{2}\right)-\left(\sum y\right)^{2}}}$

where $n$ is the number of pairs of data and the value of $\rho$ is $-1 \leq \rho \leq+1$. The "+" and "-" signs are used for positive linear correlations and negative linear correlations, respectively. The larger the absolute value of $\rho$, the stronger the linear correlation relationship. It is significant when the absolute value of correlation coefficient is greater than 0.236 at a $99.9 \%$ confidence level.

\subsection{Elasticity model for runoff}

Schaake (1990) proposed the concept of climate elasticity to evaluate the effect of climate change on runoff (see also Dooge, 1992; Dooge et al., 1999). The climate elasticity of runoff is defined as the proportional change of runoff divided by the proportional change of a climate variable such as precipitation, which can be expressed as:

$\frac{\Delta R_{i}}{\bar{R}}=\varepsilon_{R}^{P} \frac{\Delta P_{i}}{\bar{P}}$,

where $\frac{\Delta R_{i}}{\bar{R}}=\frac{R_{i}-\bar{R}}{\bar{R}}$ and $\frac{\Delta P_{i}}{\bar{P}}=\frac{P_{i}-\bar{P}}{\bar{P}}$ represent annual percentage departures from mean annual values for total runoff and precipitation, respectively; $\varepsilon_{R}^{P}$ represents the elasticity of total runoff to precipitation change. Sankarasubramanian et al. (2001) estimated the runoff elasticity to precipitation change as: $\varepsilon_{R}^{P}=\operatorname{mean}\left(\frac{d R_{i} / \bar{R}}{d P_{i} / \bar{P}}\right)=\operatorname{mean}\left(\frac{R_{i}-\bar{R}}{P_{i}-\bar{P}} \cdot \frac{\bar{P}}{\bar{R}}\right)$. Ma

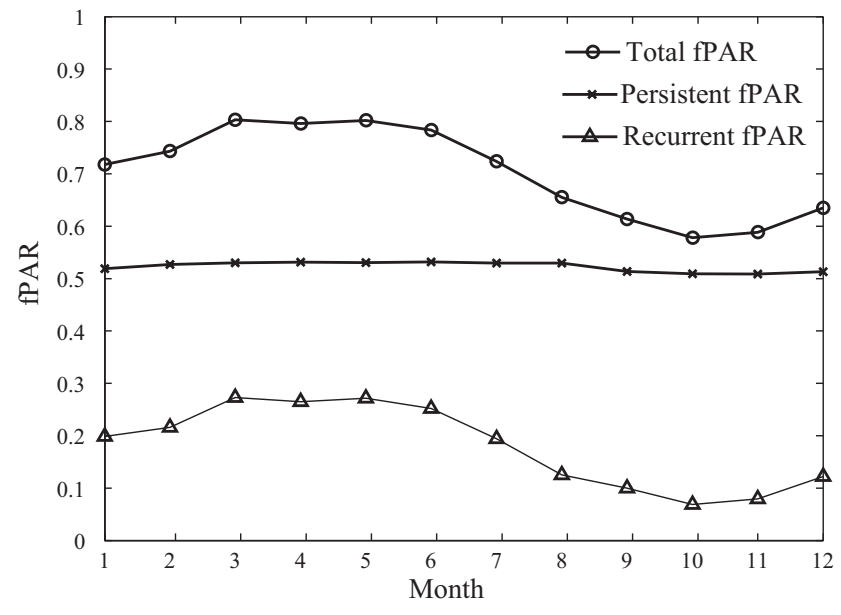

Fig. 2. An example (catchment code: 110003) of mean monthly fPAR based on separating total fPAR $\left(F_{\mathrm{t}}\right)$ into recurrent fPAR $\left(F_{\mathrm{r}}\right)$ and persistent $\operatorname{fPAR}\left(F_{\mathrm{p}}\right)$ from the 26-year data.

et al. (2010) introduced the effect of annual mean temperature into a two-parameter climate elasticity model as:

$\frac{\Delta R_{i}}{\bar{R}}=\varepsilon_{R}^{P} \frac{\Delta P_{i}}{\bar{P}}+\varepsilon_{R}^{T} \Delta T_{i}$

where $\Delta T_{i}$ represents the change in annual mean temperature compared to the long-term mean temperature $\left(\Delta T_{i}=T_{i}-\bar{T}\right)$ and $\varepsilon_{R}^{T}$ is the total runoff elasticity to temperature change, meaning the percent change of runoff coming from the change of temperature by $1^{\circ} \mathrm{C}$.

Inter-annual variability (i.e. carry-over) of soil moisture storage can also influence changes in annual runoff. Due to lack of observation of soil moisture, we use the antecedent precipitation as a proxy of soil moisture in this study. Therefore, Eq. (4) can be re-written as:

$\frac{\Delta R_{i}}{\bar{R}}=\varepsilon_{R}^{P} \frac{\Delta P_{i}}{\bar{P}}+\varepsilon_{R}^{P_{-1}} \frac{\Delta P_{-1}}{\bar{P}}+\ldots+\varepsilon_{R}^{P_{-n}} \frac{\Delta P_{-n}}{\bar{P}}+\varepsilon_{R}^{T} \Delta T_{i}$

where $\varepsilon_{R}^{P_{-1}}, \ldots, \varepsilon_{R}^{P_{-n}}$ represent the total runoff elasticity to soil moisture storage change, meaning the percent change of runoff coming from the change of precipitation in previous years. Similarly, we derive the multi-parameter elasticity models for surface runoff and subsurface runoff as follows:

$\frac{\Delta R_{\mathrm{S}, i}}{\bar{R}_{\mathrm{S}}}=\varepsilon_{R_{\mathrm{S}}}^{P} \frac{\Delta P_{i}}{\bar{P}}+\varepsilon_{R_{\mathrm{S}}}^{P_{-1}} \frac{\Delta P_{-1}}{\bar{P}}+\ldots+\varepsilon_{R_{\mathrm{S}}}^{P_{-n}} \frac{\Delta P_{-n}}{\bar{P}}+\varepsilon_{R_{\mathrm{S}}}^{T} \Delta T_{i}$

$\frac{\Delta R_{g, i}}{\bar{R}_{g}}=\varepsilon_{R_{g}}^{P} \frac{\Delta P_{i}}{\bar{P}}+\varepsilon_{R_{g}}^{P_{-1}} \frac{\Delta P_{-1}}{\bar{P}}+\ldots+\varepsilon_{R_{g}}^{P_{-n}} \frac{\Delta P_{-n}}{\bar{P}}+\varepsilon_{R_{g}}^{T} \Delta T_{i}$

where $\varepsilon_{R_{\mathrm{S}}}^{P}$ and $\varepsilon_{R_{\mathrm{S}}}^{T}$ are the precipitation and temperature elasticity of surface runoff; $\varepsilon_{R_{g}}^{P}$ and $\varepsilon_{R_{g}}^{T}$ are the precipitation and temperature elasticity of subsurface runoff; $\varepsilon_{R_{\mathrm{S}}}^{P_{-1}}, \ldots, \varepsilon_{R_{\mathrm{S}}}^{P_{-n}}$ represent the soil moisture storage elasticity of surface runoff; and $\varepsilon_{R_{g}}^{P_{-1}}, \ldots, \varepsilon_{R_{g}}^{P_{-n}}$ represent the soil moisture storage elasticity of subsurface runoff. 

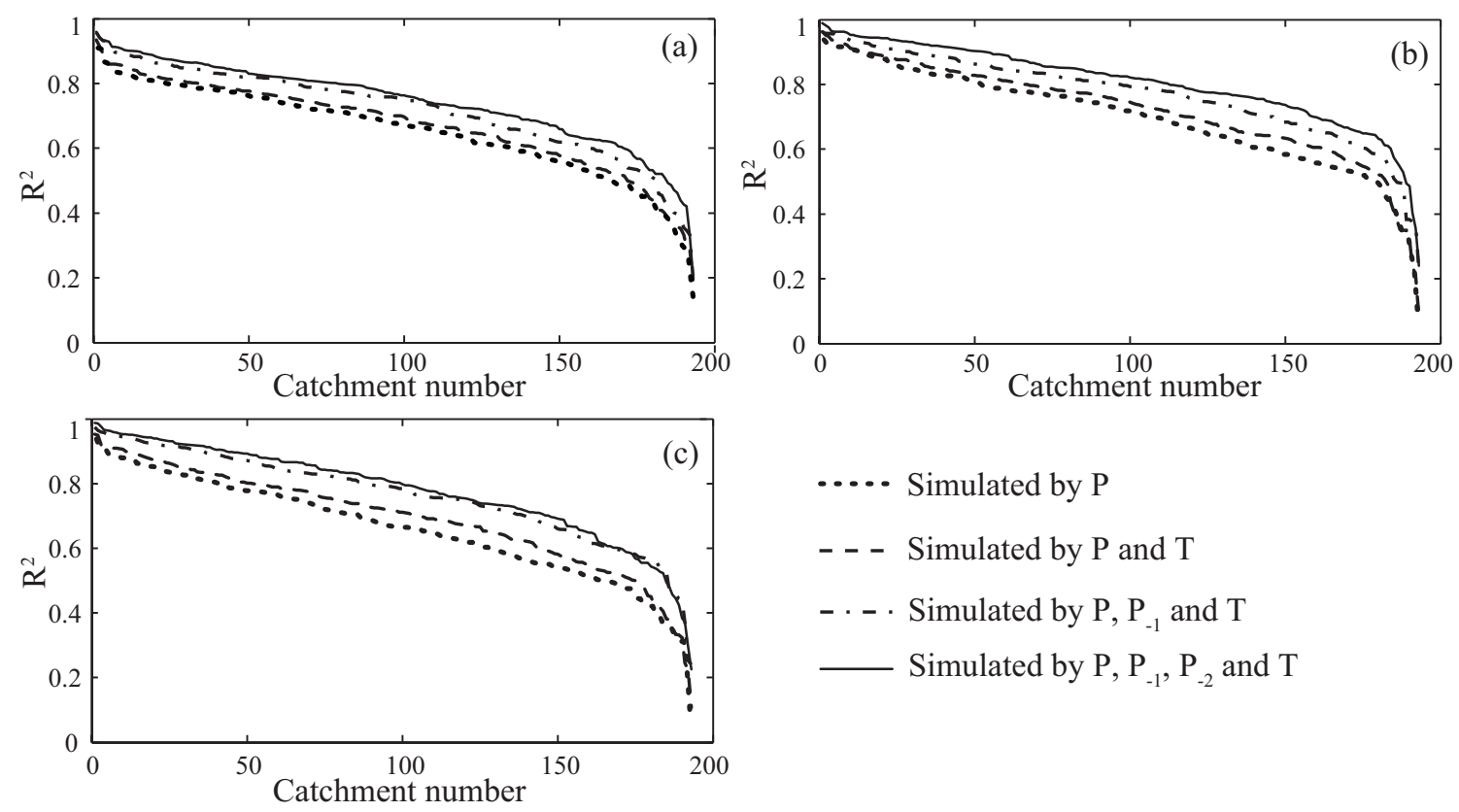

Simulated by $\mathrm{P}, \mathrm{P}_{-1}, \mathrm{P}_{-2}$ and $\mathrm{T}$

Fig. 3. Statistical distributions of coefficient of determination $\left(R^{2}\right)$ in elasticity esimation for (a) annual total runoff, (b) annual surface runoff and (c) annual subsurface runoff. Note that $P$ represents the current year's precipitation, $P_{-1}$ represents last year's precipitation, $P_{-2}$ represents the year before last year's precipitation and $T$ represents the current year's mean temperature.

The data period is split into two parts, and the elasticity model described by Eqs. (3)-(7) are calibrated and validated based on the two parts of the data, respectively. Figure 3 shows validation results of the elasticity models for annual total runoff $(R)$, annual surface runoff $\left(R_{\mathrm{S}}\right)$ and annual subsurface runoff $\left(R_{g}\right)$. On the basis of the annual precipitation elasticity model, by adding a temperature term in the model, prediction of the changes in catchment annual total runoff and its components was found to be improved. We also added other climatic factors, such as potential evapotranspiration and radiation, but the accuracy of the runoff elasticity model showed little improvement. By adding the antecedent precipitation, the elasticity models for annual $R$, $R_{\mathrm{S}}$ and $R_{g}$ are greatly improved. This suggests that carryover of soil moisture storage has a significant effect on the change of catchment runoff and its components. From Fig. 3, we can see that it needs to consider the antecedent precipitation in at least 2 previous years in order to accurately predict the changes of catchment runoff and its components.

The elasticity model performs better in terms of predicting the change of annual total runoff than predicting changes of surface and subsurface runoff components. This might be caused by the error introduced by the baseflow separation; as well, it could be caused by other factors such as topography and soils. Moreover, the shorter data period is used for $R_{\mathrm{S}}$ and $R_{g}$ compared to the total runoff data. The data period of annual surface and subsurface runoff is between 10 to 18 years, while the data period of total runoff is between 15 to 26 years (the most catchments have more than 25 -years data records). The longer the data series, the better the estimation of statistics regression parameters.

\subsection{Elasticity model for vegetation}

Taking into consideration the seasonal fluctuation of vegetation cover, especially for non-woody vegetation (also see Fig. 2), we use monthly maximum values of $F_{\mathrm{t}}, F_{\mathrm{p}}$ and $F_{\mathrm{r}}$ instead of the annual mean values in the elasticity model for vegetation cover. Redefining the month with maximum monthly $F_{\mathrm{t}}$ as the end of the year, we then divide the year into a growing season and a non-growing season. The length of the growing season along the coast in south-eastern and south-western Australia could be as much as nine months, but it decreases gradually from the coast to the interior according to both the intensity and seasonal distribution of precipitation (FAO, 1978; McQueen, 2002). In order to facilitate the processing and maintain consistency, the growing season in this paper is considered as a consecutive period of six months (Kahn et al., 2005), with the month of maximum monthly $F_{\mathrm{t}}$ taken as the end of growing season, and the remaining (first) six months of the year then taken as the nongrowing season. The annual precipitation is re-calculated for growing season $\left(P_{\text {grow }}\right)$ and non-growing season $\left(P_{\text {nongrow }}\right)$. The precipitation during non-growing season can affect the change of soil moisture storage. The temperature and incoming shortwave radiation are averaged during the vegetation growing season. So the elasticity models could be written as: 

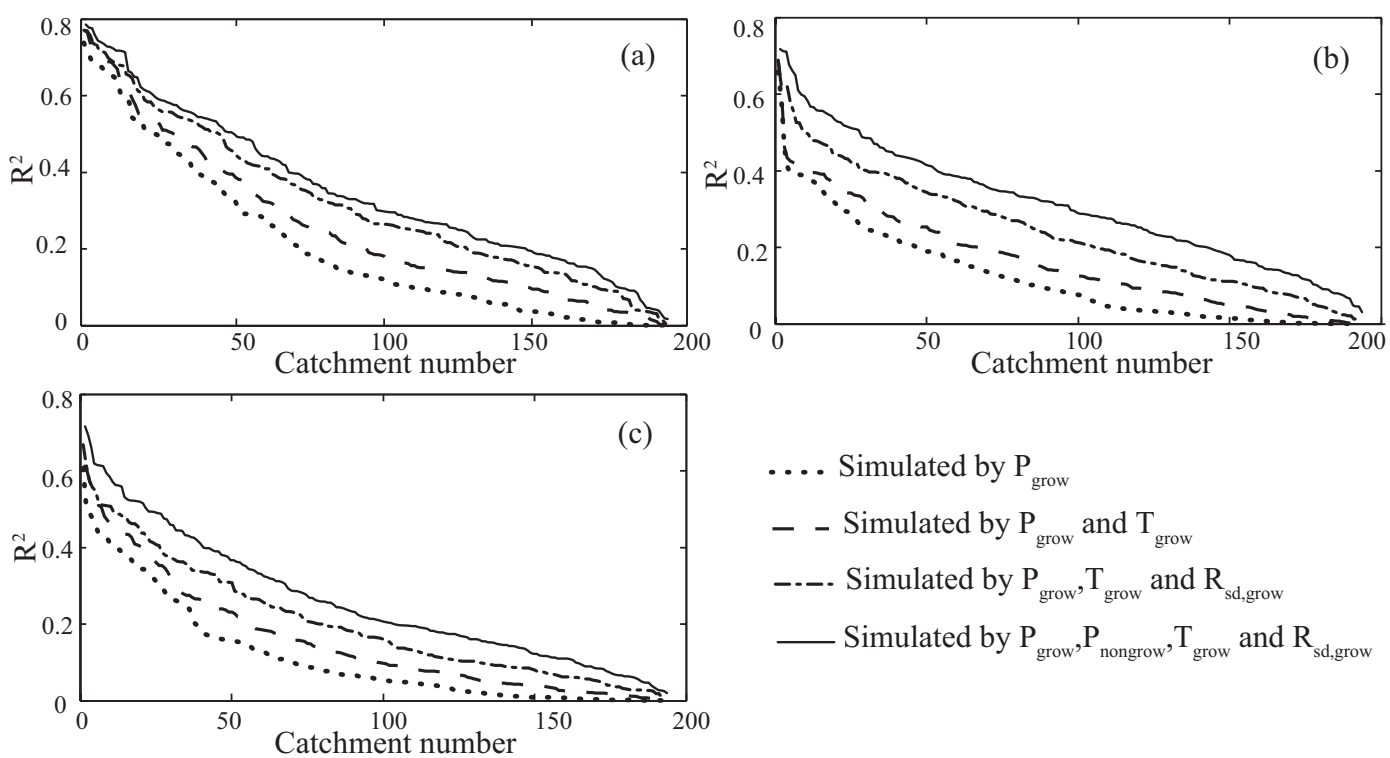

Fig. 4. Statistical distributions of coefficient of determination $\left(R^{2}\right)$ in elasticity estimation for (a) total fPAR $\left(F_{\mathrm{t}}\right)$, $(\mathbf{b})$ persistent fPAR $\left(F_{\mathrm{p}}\right)$ and $(\mathbf{c})$ recurrent fPAR $\left(F_{\mathrm{r}}\right)$. Note that $P_{\text {grow }}$ represents precipitation during growing season, $P_{\text {nongrow }}$ represents precipitation during non-growing season, $T$ represents mean temperature during growing season and $R_{\mathrm{Sd}}$ represents mean incoming shortwave radiation during growing season.

$$
\begin{aligned}
\frac{\Delta F_{\mathrm{t}, i}}{\bar{F}_{\mathrm{t}}} & =\varepsilon_{F_{\mathrm{t}}}^{P_{\text {grow }}} \frac{\Delta P_{\text {grow }, i}}{\bar{P}_{\text {grow }}}+\varepsilon_{F_{\mathrm{t}}}^{P_{\text {nongrow }}} \frac{\Delta P_{\text {nongrow }, i}}{\bar{P}_{\text {nongrow }}} \\
& +\varepsilon_{F_{\mathrm{t}}}^{T_{\text {grow }}} \Delta T_{\text {grow }, i}+\varepsilon_{F_{\mathrm{t}}}^{R_{\text {sd grow }}} \frac{\Delta R_{\text {sd, grow }, i}}{\bar{R}_{\text {sd, grow }}} \\
\frac{\Delta F_{\mathrm{p}, i}}{\bar{F}_{\mathrm{p}}} & =\varepsilon_{F_{\mathrm{p}}}^{P_{\text {grow }}} \frac{\Delta P_{\text {grow }, i}}{\bar{P}_{\text {grow }}}+\varepsilon_{F_{\mathrm{p}}}^{P_{\text {nongrow }}} \frac{\Delta P_{\text {nongrow }, i}}{\bar{P}_{\text {nongrow }}} \\
& +\varepsilon_{F_{\mathrm{p}}}^{T_{\text {grow }}} \Delta T_{\text {grow }, i}+\varepsilon_{F_{\mathrm{p}}}^{R_{\text {gdow }}} \frac{\Delta R_{\text {sd, grow }, i}}{\bar{R}_{\text {sd, grow }}} \\
\frac{\Delta F_{\mathrm{r}, i}}{\bar{F}_{\mathrm{r}}} & =\varepsilon_{F_{\mathrm{r}}}^{P_{\text {grow }}} \frac{\Delta P_{\text {grow }, i}}{\bar{P}_{\text {grow }}}+\varepsilon_{F_{\mathrm{r}}}^{P_{\text {nongrow }}} \frac{\Delta P_{\text {nongrow }, i}}{\bar{P}_{\text {nongrow }}} \\
& +\varepsilon_{F_{\mathrm{r}}}^{T_{\text {grow }}}
\end{aligned}
$$

where $P_{\text {grow }}, T_{\text {grow }}$ and $R_{\text {sd,grow }}$ represent precipitation, temperature and incoming shortwave radiation, respectively, during the growing season; $P_{\text {nongrow }}$ represents precipitation during non-growing season. $\varepsilon^{P_{\text {grow }}}, \varepsilon^{T_{\text {grow }}}$ and $\varepsilon^{R_{\text {sd,grow }}}$ are the growing season precipitation, temperature and radiation elasticity, respectively, of vegetation cover; $\varepsilon^{P_{\text {nongrow }}}$ represents the soil moisture storage elasticity of vegetation cover.

The elasticity models described by Eqs. (8)-(10) are calibrated first, and the validation of the elasticity models for maximum monthly total vegetation cover $\left(F_{\mathrm{t}}\right)$, woody cover $\left(F_{\mathrm{p}}\right)$ and non-woody cover $\left(F_{\mathrm{r}}\right)$ are shown in Fig. 4 . We can see that the elasticity models can be used to predict the changes in catchment maximum monthly vegetation cover.
On the basis of the precipitation elasticity model, by adding a temperature term and a radiation term in the model, prediction of the changes in catchment vegetation cover is improved substantially. By adding the antecedent precipitation during the non-growing season to reflect the effect of soil moisture storage, the elasticity models for maximum monthly vegetation cover are greatly improved. The elasticity model performs better in predicting the change of maximum monthly total vegetation cover than in predicting the changes of woody and non-woody vegetation cover. This might be caused by errors introduced in the separation of total fPAR $\left(F_{\mathrm{t}}\right)$ into persistent fPAR $\left(F_{\mathrm{p}}\right)$ and recurrent fPAR $\left(F_{\mathrm{r}}\right)$.

Compared to Fig. 3, Fig. 4 shows that the accuracies of the elasticity model for $F_{\mathrm{t}}, F_{\mathrm{p}}$ and $F_{\mathrm{r}}$ are lower than that for runoff and its components. One reason might be that the monthly vegetation data will smooth the daily variability of vegetation cover. Several researchers (Gallo et al., 2004, 2005; Tucker et al., 2005; Brown et al., 2006) have compared the normalized difference vegetation index (NDVI) estimated from AVHRR and MODIS and found that the two datasets are not of the same quality. The fPAR data from AVHRR might also contain some errors. Figure 4 also shows that the elasticity model for $F_{\mathrm{r}}$ has the lowest accuracy, which may come from the error introduced in $F_{\mathrm{p}}$ and $F_{\mathrm{r}}$ separation and from the complex composition of $F_{\mathrm{r}}$ from grass and deciduous forest. 

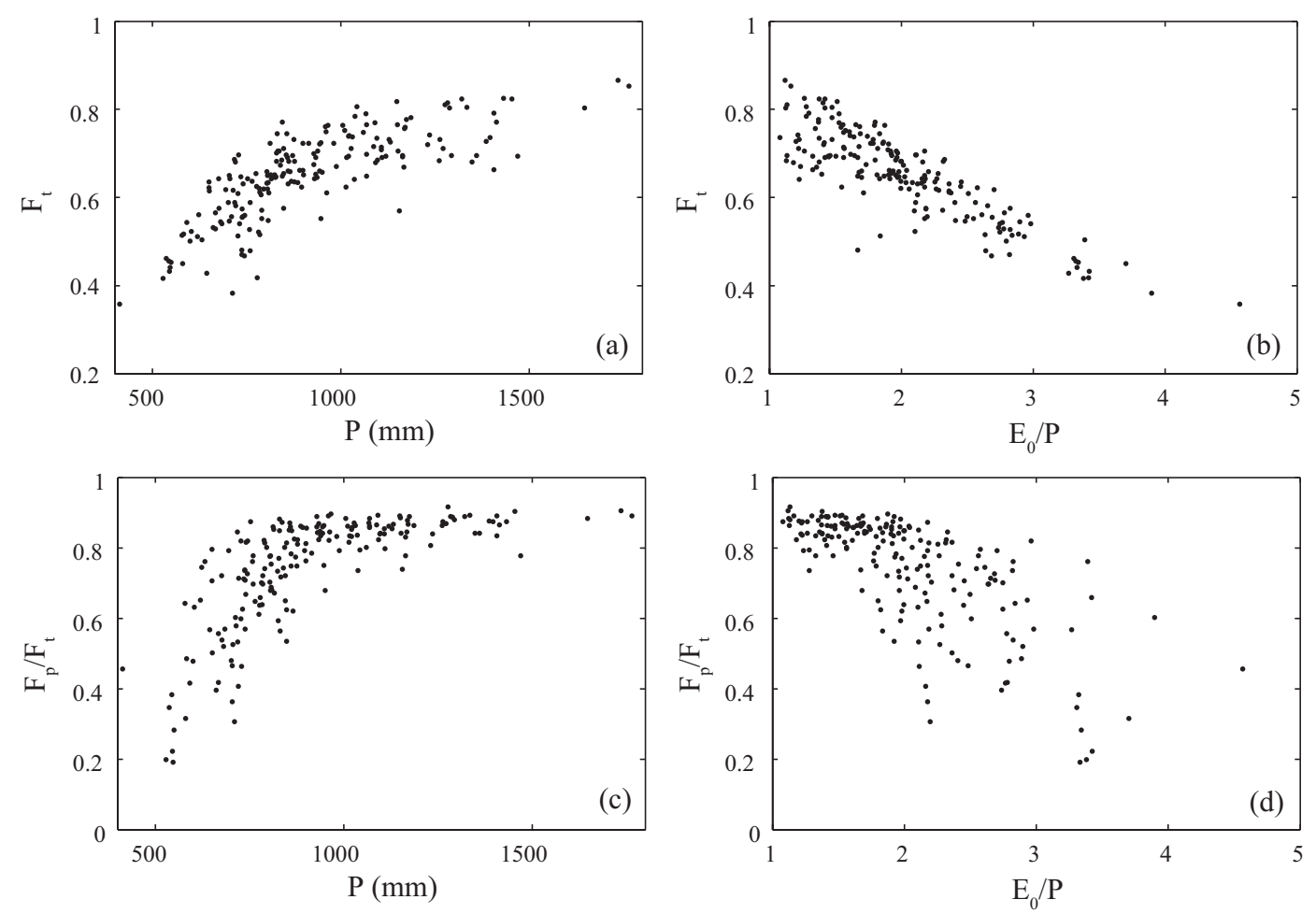

Fig. 5. Scatter plots of comparing long-term average vegetation cover (represented by mean annual value of fPAR) against mean annual precipitation $(P)$ and dryness index $\left(E_{0} / P\right)$ : (a) and (b) total vegetation cover (represented by $\left.F_{\mathrm{t}}\right),(\mathbf{c})$ and (d) fraction of woody vegetation cover (represented by $F_{\mathrm{p}} / F_{\mathrm{t}}$ ).

\section{Results}

\subsection{General pattern among climate, water balance and vegetation cover}

Figure 5a shows the relationship between mean annual vegetation cover $(\bar{F})$ and mean annual precipitation $(\bar{P})$ and Fig. 5b shows the relationship between $\bar{F}$ and dryness index $\left(E_{0} / P\right)$ across the 193 study catchments. Total fPAR is positively correlated to total precipitation with the linear correlation coefficient of 0.77 and is negatively correlated to dryness index, which tells us that vegetation growth is governed by water availability (as measured by annual precipitation) in water-limited regions (as in the case in Australia), and that vegetation cover increases with precipitation and decreases with dryness index. When annual precipitation is large enough (larger than about $1200 \sim 1400 \mathrm{~mm} \mathrm{yr}^{-1}$ for the study areas), vegetation cover tends to be saturated, as $\bar{F}_{\mathrm{t}}$ asymptotes to a maximum value. As shown in Fig. $5 \mathrm{c}$ and d, the proportion of woody vegetation $\left(F_{\mathrm{p}} / F_{\mathrm{t}}\right)$ increases with precipitation and decreases with dryness index, and woody vegetation is the dominant type in the catchments where $\bar{P}$ is larger than $800 \mathrm{~mm} \mathrm{yr}^{-1}$ and $E_{0} / P$ is less than about 2.0 . As $F_{\mathrm{r}} / F_{\mathrm{t}}$, the proportion of non-woody vegetation $\left(F_{\mathrm{r}} / F_{\mathrm{t}}\right)$ decreases with precipitation and increases with dryness index. This means that vegetation is dense in catchments where woody vegetation is dominant, but is sparse in catchments where non-woody vegetation is dominant. The scattered points in Fig. $5 \mathrm{c}$ and $\mathrm{d}$ are from non-woody vegetation dominated catchments with a lower value of $\bar{P}$ and a higher value of $E_{0} / P$. This may be caused by the annual average of $F_{\mathrm{r}}$ for the seasonal vegetation. On the other hand, vegetation cover can also be related to soil and topographical conditions even when the climate condition is similar, which may explain the large scatter.

Table 1 presents the estimated correlation coefficients between mean annual vegetation cover $(\bar{F})$ and water balance components $(\bar{R}, \bar{E}, \overline{R / P}, \overline{E / P})$ based on linear correlation analysis. Table 1 (together with Fig. 5) is used to describe the spatial characteristics of long-term catchment water balance with respect to both vegetation cover and climate. Among the 193 study catchments, most of them are woody vegetation dominated. Therefore, there are positive correlations between $F_{\mathrm{t}}\left(F_{\mathrm{p}}\right)$ and $R(E, R / P)$ and negative correlation between $F_{\mathrm{t}}\left(F_{\mathrm{p}}\right)$ and $E / P$. Increase of woody vegetation cover causes decrease of non-woody vegetation cover in the study areas. The negative correlations between $F_{\mathrm{r}}$ and $R(E$, $R / P)$ and positive correlation between $F_{\mathrm{r}}$ and $E / P$ come from the negative relationship between $F_{\mathrm{p}}$ and $F_{\mathrm{r}}$. Likewise, Fig. 6 presents scatter plots relating mean annual vegetation cover and various water balance components. As shown in Fig. 6c, the relationship between $R / P$ and $F_{\mathrm{t}}$ indicates that 

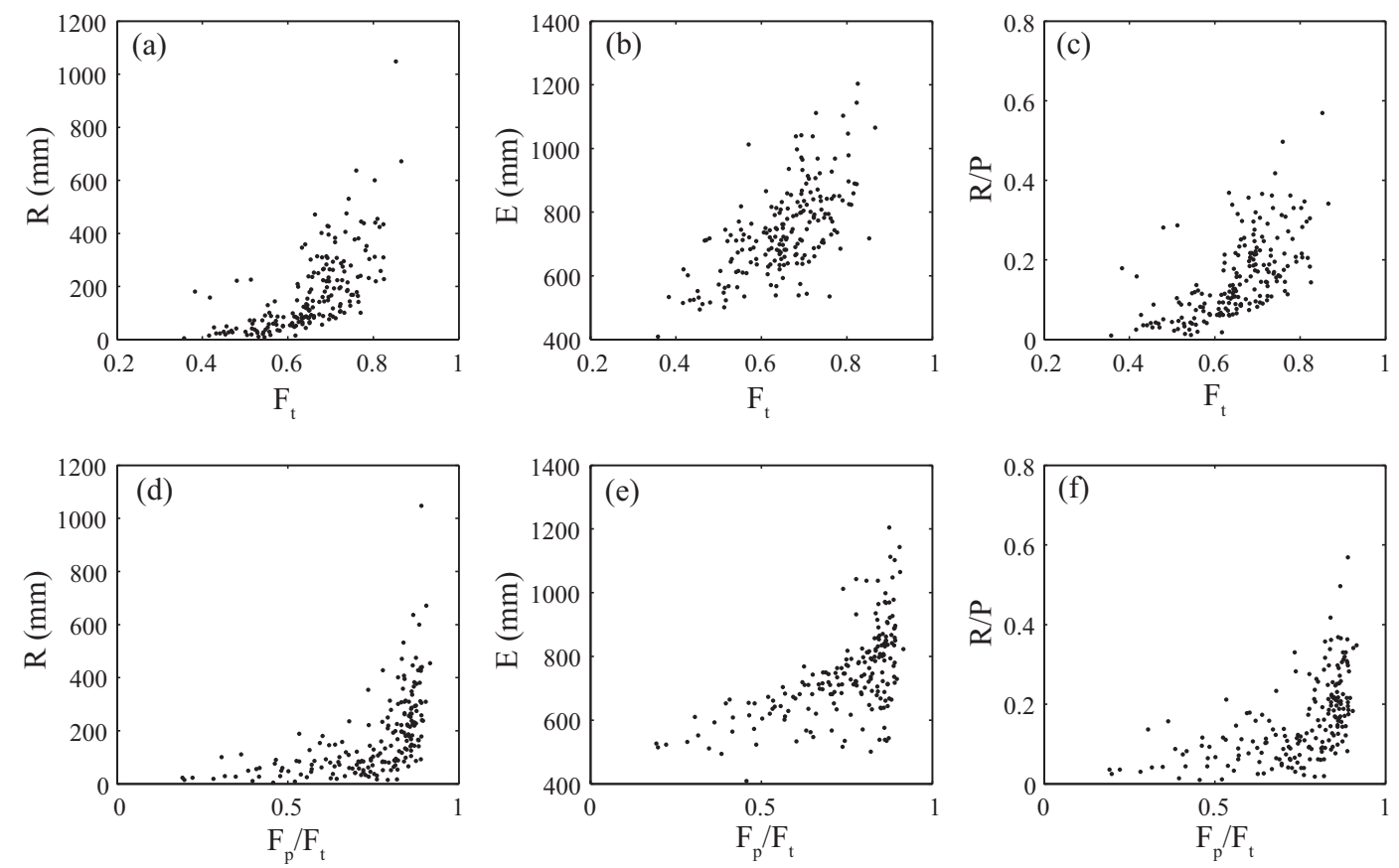

Fig. 6. Scatter plots of mean annual water balance components (total runoff, $R$ and evapotranspiration, $E$ ), mean annual water balance indexes (runoff coefficient, $R / P$ ) against long-term average vegetation cover, including total vegetation (represented by $F_{\mathrm{t}}$ ) and fraction of woody vegetation (represented by $F_{\mathrm{p}} / F_{\mathrm{t}}$ ).

Table 1. Correlation coefficients between vegetation cover and water balance components over the 193 study catchments.

\begin{tabular}{lrrrr}
\hline & $R(\mathrm{~mm})$ & $E(\mathrm{~mm})$ & \multicolumn{1}{c}{$R / P$} & \multicolumn{1}{c}{$E / P$} \\
\hline Total fPAR $\left(F_{\mathrm{t}}\right)$ & 0.653 & 0.634 & 0.623 & -0.615 \\
Persistent fPAR $\left(F_{\mathrm{p}}\right)$ & 0.676 & 0.671 & 0.647 & -0.639 \\
Recurrent fPAR $\left(F_{\mathrm{r}}\right)$ & -0.490 & -0.506 & -0.472 & 0.468 \\
\hline
\end{tabular}

partitioning of annual precipitation into runoff increases with vegetation. Negative relationship between $E / P$ and $F_{\mathrm{t}}$ could be obtained from $E / P=1-R / P$. Because most catchments are woody vegetation dominated, $F_{\mathrm{p}} / F_{\mathrm{t}}$ has similar relationships with the water balance components as $F_{\mathrm{t}}$ (see Fig. 6df). Figure $6 \mathrm{~d}$ and e indicates that $R$ and $E$ are large in catchments where persistent vegetation is dominant, which means that runoff and evapotranspiration have a positive relationship with vegetation cover in catchments where woody vegetation is dominant and annual precipitation is relatively high. This comes from the positive relationship between $F_{\mathrm{p}} / F_{\mathrm{t}}$ and $P$ shown in Fig. 5b. Because $F_{\mathrm{r}} / F_{\mathrm{t}}=1-F_{\mathrm{p}} / F_{\mathrm{t}}, R$ and $E$ are small in catchments where non-woody vegetation is dominant and annual precipitation is relatively small. Figure $6 \mathrm{f}$ shows that partitioning of annual precipitation into runoff increases with persistent vegetation. The negative relationship of $R / P \sim F_{\mathrm{r}} / F_{\mathrm{t}}$, which comes from the negative relation between $F_{\mathrm{p}} / F_{\mathrm{t}}$ and $F_{\mathrm{r}} / F_{\mathrm{t}}$, indicates that partitioning of annual
Table 2. Correlation coefficients between vegetation cover and runoff components (including surface runoff, subsurface runoff and their ratios to total runoff) over the 193 study catchments.

\begin{tabular}{lrrrr}
\hline & $R_{g}(\mathrm{~mm})$ & $R_{\mathrm{S}}(\mathrm{mm})$ & \multicolumn{1}{c}{$R_{g} / R$} & \multicolumn{1}{c}{$R_{\mathrm{S}} / R$} \\
\hline Total fPAR $\left(F_{\mathrm{t}}\right)$ & 0.637 & 0.549 & 0.354 & -0.354 \\
Persistent fPAR $\left(F_{\mathrm{p}}\right)$ & 0.655 & 0.572 & 0.277 & -0.277 \\
Recurrent fPAR $\left(F_{\mathrm{r}}\right)$ & -0.470 & -0.420 & -0.090 & 0.090 \\
\hline
\end{tabular}

precipitation into runoff decreases with proportion of recurrent vegetation. Therefore, vegetation cover could be an important factor for determining the general characteristics of catchment water balance (Yang et al., 2006, 2009).

We next look at the relationship between runoff components and vegetation type. Table 2 shows the correlation coefficients between mean annual vegetation cover $(\bar{F})$ and runoff components $\left(\bar{R}_{\mathrm{S}}, \bar{R}_{g}, \overline{R_{\mathrm{S}} / R}, \overline{R_{g} / R}\right)$ are based on linear correlation analysis. Figure 7 shows the relationship between the ratio of subsurface runoff to total runoff $\left(R_{g} / R\right)$ and vegetation type. The scattered points in Fig. 7 are affected by many factors, such as the distribution and intensity of precipitation, land use, soil infiltration capacity and localized topographic and edaphic factors (Donohue et al., 2009), the indirect function between vegetation and surface/subsurface runoff, the errors from baseflow separation, and the separation of persistent and recurrent fPAR. From 

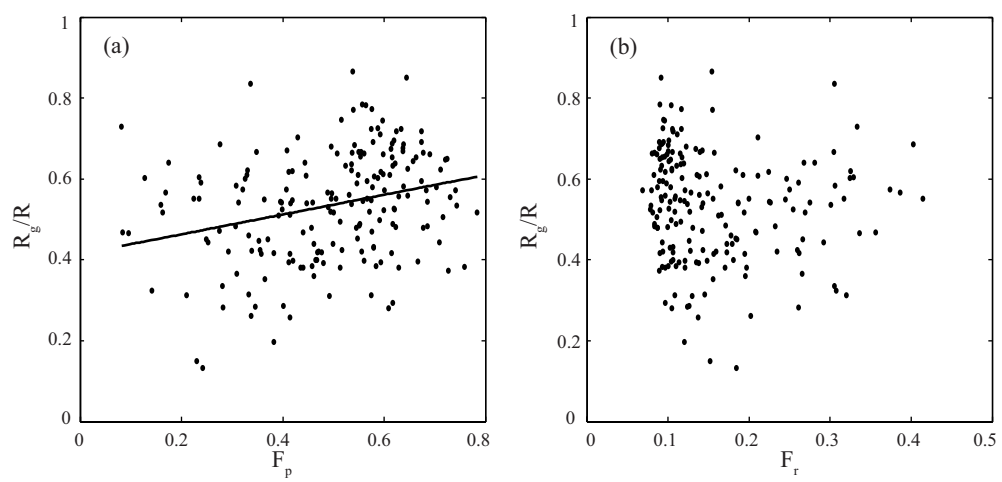

Fig. 7. Scatter plots of the ratio of subsurface runoff to total runoff $\left(R_{g} / R\right)$ againt $(\mathbf{a})$ persistent fPAR $\left(F_{\mathrm{p}}\right.$, represents woody vegetation cover) and (b) recurrent $\operatorname{PPAR}\left(F_{\mathrm{r}}\right.$, represents non-woody vegetation cover).

Table 2 and Fig. 7, we can see that both $R_{\mathrm{S}}$ and $R_{g}$ are positively correlated to $F_{\mathrm{t}}$ and $F_{\mathrm{p}}$ (with a correlation coefficient larger than 0.5 ), but negatively related to $F_{r}$ (with a correlation coefficient less than 0.5 ). Mean annual $R_{g} / R$ increases with woody vegetation cover, but the correlation is relatively weak. Non-woody vegetation cover is not significantly related to this ratio. This implies that woody vegetation can increase rainfall infiltration, and consequently change the partitioning of total runoff into surface and subsurface runoff.

\subsection{Impact of climate variation on catchment total runoff and runoff components}

Using the entire data records from the 193 study catchments, the climate elasticity of annual total runoff, surface runoff and subsurface runoff was estimated through step-wise regression. The $R^{2}$ statistic, the $F$ statistic and its $p$ value, and an estimate of the error variance are calculated for each catchment. For the climate elasticity of annual total runoff $(R)$, there are 167 catchments with $F_{\text {test }}>F_{0.005}$ and $p$-value in $F$ statistics less than 0.05 . The coefficient of determinant $\left(R^{2}\right)$ of the total runoff elasticity model ranges from 0.58 to 0.96 , with a mean value of 0.77 (the median value is 0.79 ), the $F$ statistic ( $F_{\text {test }}$ ) ranges from 6.10 to 104.60 , with a mean value of 19.94 (the median value is 16.39) and the error variance $\left(\sigma^{2}\right)$ ranges from 0.02 to 0.99 , with a mean value of 0.23 (the median value is 0.17 ). From the results of elasticities, we can see that current year's precipitation $(P)$ is the most important factor for total runoff, a $+1 \%$ change of $P$ could cause a $+3.35 \%$ (the median value is $+3.22 \%$ ) change of $R$ on average. The significance of other controlling factors is in order of annual precipitation in the previous years $\left(P_{-1}\right.$ and $P_{-2}$ ), which can represent the effect of soil moisture storage carry-over, and current year's annual mean temperature $(T)$. Increase of antecedent precipitation $P_{-1}$ and $P_{-2}$ could produce mostly a positive effect on the change of runoff. On average, a $+1 \%$ change of $P_{-1}$ and $P_{-2}$ could produce a $+0.64 \%$ (the median value is $+0.61 \%$ ) and a $+0.29 \%$ (the median value is $+0.22 \%$ ) change of $R$, respectively. Change of $T$ by a $+1{ }^{\circ} \mathrm{C}$ could cause a $-0.05 \%$ (the median value is $-0.10 \%$ ) change of $R$ on average.

As discussed in Sect. 3, the major controlling factor on the hydrological partitioning is different for the catchments with woody and non-woody dominated vegetation, respectively. Therefore, we classify the 167 catchments into two groups according to the dominant vegetation type. The group of woody vegetation dominated catchments is relatively humid with $E_{0} / P<2.0$, and the group of non-woody vegetation dominated catchments is relatively dry with $E_{0} / P \geq 2.0$. The elasticities are then recalculated in these two groups. The quartile maps of climate elasticity parameters to $R$ for these two groups are plotted in Fig. 8a and b. The elasticity of $R$ to $P\left(\varepsilon_{R}^{P}\right)$ is 4.09 for 60 non-woody vegetation dominated catchments and 2.94 for 107 woody vegetation dominated catchments on average, which means that runoff in catchments with relatively drier climate are more sensitive to current year's precipitation. Similar results are found for the elasticities of $R$ to $P_{-1}$ and $P_{-2}\left(\varepsilon_{R}^{P_{-1}}\right.$ and $\left.\varepsilon_{R}^{P_{-2}}\right)$. But the elasticity of $R$ to $T\left(\varepsilon_{R}^{T}\right)$ is 0.06 for non-woody vegetation dominated catchments and -0.12 for woody vegetation dominated catchment on average. The change of temperature mainly impacts on the evapotranspiration and then on the soil moisture. Runoff change depends on precipitation change and is related to the change in soil moisture, which may alter the mechanism of runoff generation.

For the climate elasticity of annual surface runoff $\left(R_{\mathrm{S}}\right)$, there are 112 catchments with $F_{\text {test }}>F_{0.005}$ and the $p$-value of the $F$ statistics is less than 0.05 . From the results of elasticities, we can see that change of current year's annual precipitation $(P)$ is also the most important factor controlling the change of surface runoff, and on average, a $+1 \%$ change of $P$ could cause a $+3.47 \%$ (the median value is $+3.12 \%$ ) change of $R_{\mathrm{S}}$. On average, a $+1 \%$ change of $P_{-1}$ and $P_{-2}$ (the antecedent precipitation) could produce a $+0.33 \%$ (the median value is $+0.27 \%$ ) and a $+0.06 \%$ (the median value is $+0.11 \%$ ) change of $R_{\mathrm{S}}$, respectively. Change of $T$ by a 

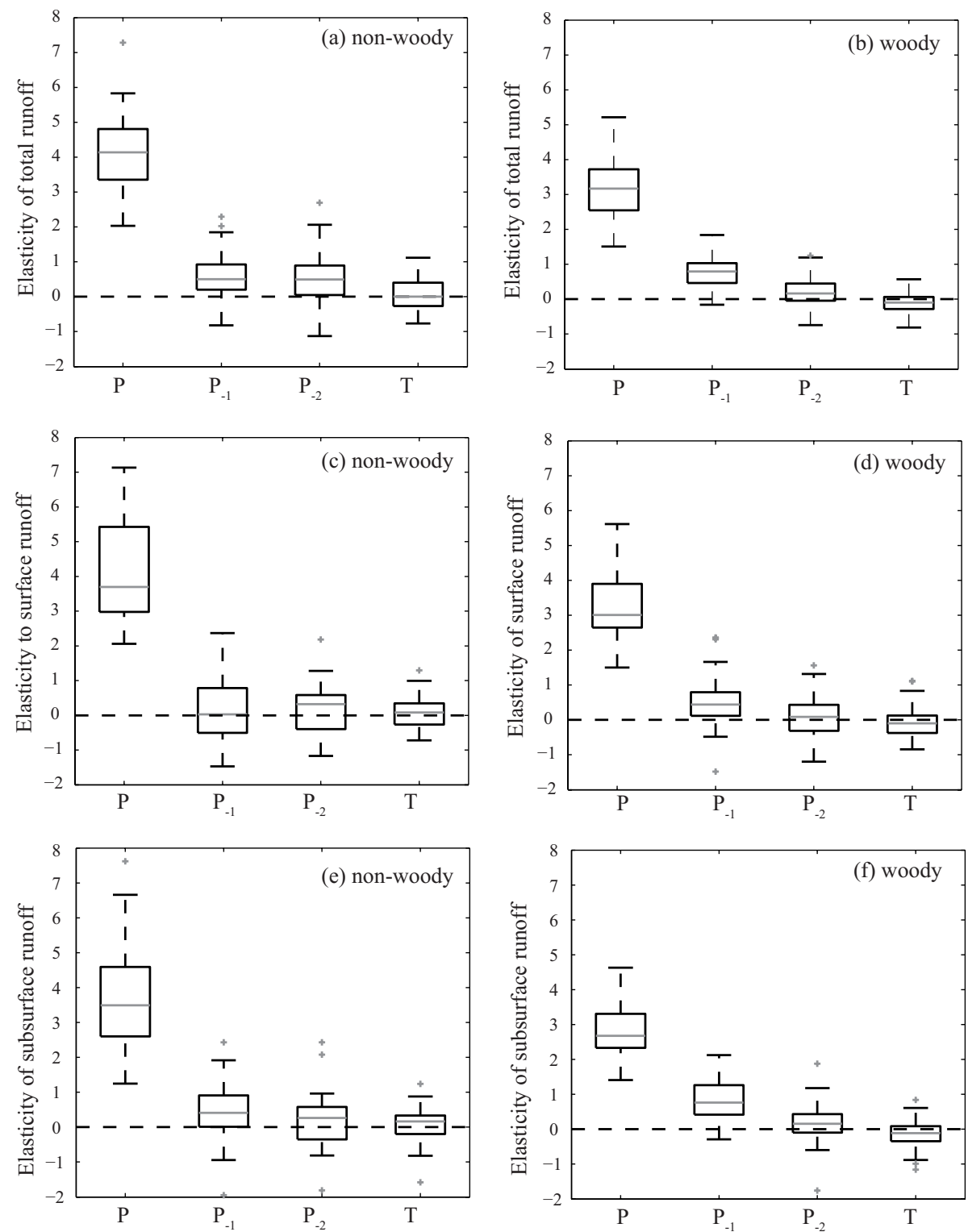

Fig. 8. The quantile map of climate elasticity parameters of annual total runoff for (a) 60 non-woody vegetation dominated catchments (with $E_{0} / P \geq 2.0$ ) and (b) 107 woody vegetation dominated catchments (with $E_{0} / P<2.0$ ), annual surface runoff for (c) 36 non-woody vegetation dominated catchments and (d) 76 woody vegetation dominated catchments, subsurface runoff for (e) 29 non-woody vegetation dominated catchments and (f) 67 woody vegetation dominated catchments. The upper black line is the maximum whisker (the length of whisker is 1.5 ), the lower black line is the minimum whisker, the upper quartile is the 75th percentile, the lower quartile is the 25th percentile, the grey line is the median value, the grey cross is the point out of the whiskers. Note that $P$ represents current year's precipitation, $P_{-1}$ represents last year's precipitation, $P_{-2}$ represents the year before last year's precipitation and $T$ represents current year's temperature.

$+1{ }^{\circ} \mathrm{C}$ could cause a $-0.07 \%$ (the median value is $-0.09 \%$ ) change of $R_{\mathrm{S}}$ on average. The 112 catchments are classified into the same two groups, of which 36 catchments are nonwoody vegetation dominated and 76 catchments are woody vegetation dominated. The quartile maps of climate elasticity parameters to $R_{\mathrm{S}}$ for these two groups are plotted in Fig. 8c and d. Similar results are found for surface runoff as compared to total runoff.
For the climate elasticity of annual subsurface runoff $\left(R_{g}\right)$, there are 96 catchments with $F_{\text {test }}>F_{0.005}$ and $p$-value in $F$ statistics less than 0.05 . From the elasticity results, we can see that the change of current year's annual precipitation $(P)$ is also the most important factor affecting the change of $R_{g}$. On average, a $+1 \%$ change of $P$ could cause a $+2.89 \%$ (the median value is $+2.59 \%$ ) change of $R_{g}$, less than that to $R_{\mathrm{s}}$ and $R$. Compared to $R_{\mathrm{s}}$, the significance of $P_{-1}$ and $P_{-2}$ 

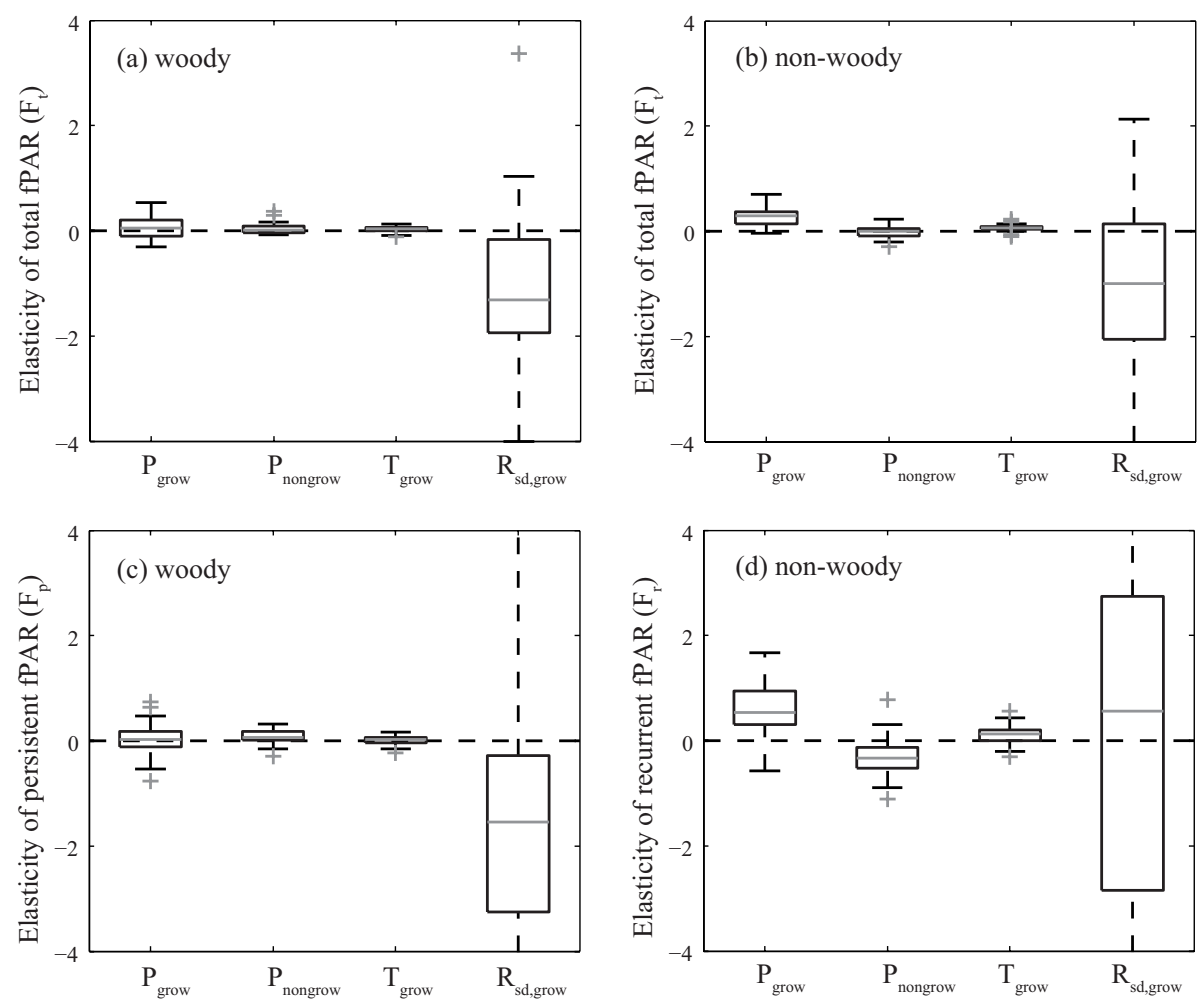

Fig. 9. The quantile map of climate elasticity parameters of (a) total fPAR for 26 woody vegetation dominated catchments (with $E_{0} / P<2.0$ ), (b) total fPAR for 48 non-woody vegetation dominated catchments (with $E_{0} / P \geq 2.0$ ), (c) persistent fPAR for 35 woody vegetation dominated catchments and (d) recurrent fPAR for 30 non-woody vegetation dominated catchments. Note that $P_{\text {grow }}$ represents precipitation during growing season, $P_{\text {nongrow }}$ represents precipitation during non-growing season, $T_{\text {grow }}$ represents mean temperature during growing season and $R_{\mathrm{sd} \text {, grow }}$ represents mean incoming shortwave radiation during growing season.

(the antecedent precipitation) is more important to $R_{g}$ and on average, a $+1 \%$ change of $P_{-1}$ and $P_{-2}$ could produce $\mathrm{a}+0.61 \%$ (the median value is $+0.58 \%$ ) and $\mathrm{a}+0.11 \%$ (the median value is $+0.08 \%$ ) change of $R_{g}$, respectively. This shows that the variability of soil moisture storage is more important to $R_{g}$ than to $R_{\mathrm{S}}$. Change of $T$ by a $+1^{\circ} \mathrm{C}$ could cause a $-0.10 \%$ (the median value is $-0.10 \%$ ) change of $R_{g}$ on average. The 96 catchments are classified into the same two groups, of which 29 catchments are non-woody vegetation dominated and 67 catchments are woody vegetation dominated. The quartile maps of climate elasticity parameters to $R_{g}$ for these two groups are plotted in Fig. 8e and f. Similar results are found for subsurface runoff as compared to total and surface runoff. The elasticities of $R_{g}$ to $P_{-1}$ and $P_{-2}$ are greater than those of $R_{\mathrm{S}}$ for both two groups on average, which also implies that the importance of soil moisture storage variability to $R_{g}$ is greater than that to $R_{\mathrm{S}}$.

\subsection{Impact of climate variability on vegetation cover}

Using the whole data records in the 193 study catchments, the climate elasticities of the maximum monthly total, woody and non-woody vegetation cover are estimated through step-wise regression. The $R^{2}$ statistic, the $F$ statistic and its $p$ value, and an estimate of the error variance are calculated for each catchment. There are 74, 63 and 48 catchments with $F_{\text {test }}>F_{0.005}$ and $p$-value in $F$ statistics less than 0.05 for the climate elasticity of maximum monthly $F_{\mathrm{t}}, F_{\mathrm{p}}$ and $F_{\mathrm{r}}$, respectively. From the results of elasticities, we can see that radiation during growing season is the most important factor influencing the change of maximum monthly vegetation cover: a $+1 \%$ change of $R_{\text {sd,grow }}$ could cause a $-1.08 \%$ (the median value is $-1.11 \%$ ), a $-1.92 \%$ (the median value is $-1.87 \%$ ) and $\mathrm{a}+1.33 \%$ (the median value is $+0.57 \%$ ) change of maximum monthly $F_{\mathrm{t}}, F_{\mathrm{p}}$ and $F_{\mathrm{r}}$, respectively. Similarly, a $+1 \%$ change of $P_{\text {grow }}$ could cause a $+0.20 \%$ (the median value is $+0.21 \%$ ), a $+0.04 \%$ (the median value is $+0.03 \%$ ) and a $+0.62 \%$ (the median value is $+0.56 \%$ ) change of maximum monthly $F_{\mathrm{t}}, F_{\mathrm{p}}$ and $F_{\mathrm{r}}$, respectively. On average, a $+1 \%$ change of $P_{\text {nongrow }}$ (precipitation in the non-growing season) could produce a $+0.01 \%$ (the median value is $+0.01 \%$ ), a $+0.12 \%$ (the median value is $+0.12 \%$ ), and a $-0.23 \%$ (the median value is $-0.28 \%$ ) change of maximum monthly $F_{\mathrm{t}}, F_{\mathrm{p}}$ and $F_{\mathrm{r}}$, respectively. Change of temperature by $\mathrm{a}+1^{\circ} \mathrm{C}$ could, on average, cause a $+0.05 \%$ (the median value is $+0.06 \%$ ), a 
$+0.03 \%$ (the median value is $0.04 \%$ ) and a $+0.05 \%$ (the median value is $+0.09 \%$ ) change of maximum monthly $F_{\mathrm{t}}, F_{\mathrm{p}}$ and $F_{\mathrm{r}}$, respectively.

The dominant vegetation type is related to the dryness of climate. The 74 catchments for total vegetation cover are classified into the same two groups as in the case of runoff, of which 48 catchments are non-woody vegetation dominated and 26 catchments are woody vegetation dominated. The quartile maps of climate elasticity parameters for total vegetation cover are presented in Fig. 9a and b. The elastcity of $F_{\mathrm{t}}$ to $P_{\text {grow }}$ is 0.27 for non-woody catchments, which is greater than that $(0.07)$ for woody catchments, which means that precipitation during growing season is more important for vegetation growth in relatively dry climates than in relatively humid climate. But the elasticity of $F_{\mathrm{t}}$ to $P_{\text {nongrow }}$ is -0.01 for non-woody catchments, which is less than that (0.05) for woody catchments, which means that soil moisture (represented by precipitation during non-growing season) is more important for vegetation growth in relatively humid climate than in relatively dry climates. The elasticity of $F_{\mathrm{t}}$ to $T_{\text {grow }}$ for non-woody catchments (0.07) is a little greater than that for woody catchments $(0.02)$. The elascity of $F_{\mathrm{t}}$ to $R_{\mathrm{sd} \text {,grow }}$ is similar for both groups. As woody vegetation dominated catchments are in relatively humid climates, 35 woody catchments in all 63 catchments are selected to recalculate the elasticities. As non-woody vegetation dominated catchments are in dry climates, 30 non-woody catchments in all 48 catchments are selected to recalculate the elasticities. The quartile maps of climate elasticity parameters for woody vegetation cover is presented in Fig. 9c and non-woody vegetation cover in Fig. 9d. The mean value of $\varepsilon_{F_{\mathrm{p}}}^{P_{\text {nongrow }}}(0.09)$ is greater than $\varepsilon_{F_{\mathrm{p}}}^{P_{\text {grow }}}(0.01)$, but $\varepsilon_{F_{\mathrm{r}}}^{P_{\text {grow }}}(0.59)$ is greater than $\varepsilon_{F_{\mathrm{r}}}^{P_{\text {nongrow }}}(-0.31)$ on average, which means that precipitation during growing season is more important to non-woody vegetation growth and soil moisture (represented by precipitation during non-growing season) is more important to woody vegetation growth. The value of $\varepsilon_{F_{\mathrm{r}}}^{T_{\text {grow }}}(0.12)$ is greater than $\varepsilon_{F_{\mathrm{p}}}^{T_{\text {grow }}}(0.01)$ on average, which implies that temperature is more important to $F_{\mathrm{r}}$ than to $F_{\mathrm{p}} \cdot \varepsilon_{F_{\mathrm{r}}}^{R_{\text {sd,grow }}}$ is 0.22 and $\varepsilon_{F_{\mathrm{p}}}^{R_{\text {sd,grow }}}$ is -1.46 on average.

Effect of precipitation during growing season $\left(P_{\text {grow }}\right)$ on non-woody vegetation cover $\left(F_{\mathrm{r}}\right)$ is more significant than that of precipitation during non-growing season $\left(P_{\text {nongrow }}\right)$, but $P_{\text {nongrow }}$ has a more significant effect on woody vegetation cover $\left(F_{\mathrm{p}}\right)$ than $P_{\text {grow }}$. We calculated the mean value and variance of vegetation cover from 1981 to 2006 for each catchment. On average, the total vegetation cover $\left(F_{\mathrm{t}}\right)$ is 0.655 and the variance is 0.004 , the woody vegetation cover $\left(F_{\mathrm{p}}\right)$ is 0.500 and the variance is 0.005 , and the non-woody vegetation cover $\left(F_{\mathrm{r}}\right)$ is 0.155 and the variance is 0.002 . But annual precipitation has a $-5.1 \mathrm{~mm} \mathrm{yr}^{-1}$ change and $\mathrm{a}-14.2 \%$ change on average. Therefore, the presence of a stable vegetation cover means that vegetation growth is a little influenced by climate variability. This is consistent with relatively smaller climate elasticity of vegetation cover shown in Fig. 9 comparing with the elasticity of annual runoff to climate change.

\section{Discussion}

The precipitation elasticity of total runoff is 3.3 on average and varies in the range 2.0-4.0 in the 167 catchments, which means that $\mathrm{a}+1 \%$ change in annual precipitation will result in $2.0-4.0 \%$ change in mean annual runoff. The mean annual precipitation and mean annual total runoff in the study catchments is about $903 \mathrm{~mm}$ and $158 \mathrm{~mm}$, respectively; therefore, an increase of annual precipitation by $9 \mathrm{~mm}$ change will result in about $3.2-6.3 \mathrm{~mm}$ (the average is $5.1 \mathrm{~mm}$ ) increase of mean annual total runoff. This is mostly consistent with similar results reported in 219 locations across Australia (Jones et al., 2005; Chiew, 2006). Detailed modeling conducted in Western Australia has shown that a $+1 \%$ change of annual precipitation would typically result in a $+2-3 \%$ change in annual runoff (Berti et al., 2004; Kitsios et al., 2008; Smith et al., 2009). For runoff components, current year's precipitation elasticity is a little higher for surface runoff (about 3.5) and lower for subsurface runoff (about 2.9) on average, which is consistent with results reported by Harman et al. (2011) in American MOPEX catchments. The temperature elasticity of total runoff is -0.05 on average (ranges from -0.8 to 1.1 ), which means that a $1^{\circ} \mathrm{C}$ increase of the annual temperature results in a $-0.05 \%$ change in annual runoff. The temperature elasticity of total runoff is very small. This can be explained that runoff change depends on precipitation change and is related to the change in soil moisture. The change of temperature mainly impacts on the evapotranspiration and then on the soil moisture. Strongly regulated by the soil with large water storage capacity, temperature elasticity of runoff is small.

In the case of the elasticity of vegetation cover with respect to precipitation change, a $1 \%$ increase of precipitation during the growing season will result in about a $0.2 \%$ increase of maximum monthly $F_{\mathrm{t}}$. Nemani et al. (2003) found that water availability strongly limits vegetation growth over $40 \%$ of Earth's vegetated surface, whereas temperature limits growth over $33 \%$ of the area and radiation over $27 \%$ of Earth's vegetated surface, whereas tropical areas are never limited by low temperatures but may have either a sustained dry season or nearly perpetual cloud cover that limits solar radiation. As shown in Fig. 9, the increase of incoming shortwave radiation causes a decrease of vegetation cover. A possible explanation for this is that an increase of solar radiation corresponds to a decrease of precipitation, and the decrease in precipitation then causes the decrease of vegetation cover. Therefore, ultimately it is the precipitation that mainly controls the vegetation growth in the study catchments. 
The vegetation cover increase corresponds to an increase of vegetation transpiration and also catchment runoff because precipitation is a common major control factor on both vegetation growth and catchment runoff partitioning. Increases in air temperature and solar radiation cause a decrease of vegetation cover but have little effect on catchment runoff. This implies that increases in air temperature and solar radiation could cause an increase of soil evaporation rather than the vegetation transpiration.

\section{Conclusions}

In this paper, we analyzed the effect of climate variability on catchment water balance and vegetation cover for 193 study catchments in Australia. Climate elasticities of runoff and vegetation cover were estimated. From all the results obtained through these analyses, we can conclude that:

1. Annual runoff, evapotranspiration and runoff coefficient increase with vegetation cover for catchments in which woody vegetation is dominant and annual precipitation is relatively high. Control of water available on annual evapotranspiration becomes stronger in nonwoody dominant catchments compared to woody dominant ones. The ratio of subsurface runoff to total runoff $\left(R_{g} / R\right)$ increases with woody vegetation cover.

2. The current year's precipitation is the most important factor affecting the change in annual total, surface and subsurface runoff. The significance of other controlling factors is in the order of the previous year's precipitation (carry-over of soil moisture storage) and current year's mean temperature. Change in current year's precipitation by a $+1 \%$ could produce about an average of a $+3.35 \%$ change of $R, \mathrm{a}+3.47 \%$ change of $R_{\mathrm{S}}$ and a $+2.89 \%$ change of $R_{g}$.

3. Regarding the climate elasticity of vegetation cover (represented by the maximum monthly $F_{\mathrm{t}}, F_{\mathrm{p}}$ and $F_{\mathrm{r}}$ ), the incoming shortwave radiation in the growing season $\left(R_{\text {sd, grow }}\right)$ is the most important factor affecting the change in vegetation cover: a change of $R_{\text {sd,grow }}$ by $+1 \%$ could produce a $-1.08 \%$ change of total vegetation cover $\left(F_{\mathrm{t}}\right)$, on average. The growing season precipitation has a more significant effect on non-woody vegetation cover than the non-growing season precipitation, but precipitation amounts in growing and non-growing seasons have almost equally important effects on woody vegetation cover.

It should be noted, however, that catchment water balance is closely linked with vegetation cover. Change of vegetation cover can affect catchment water balance by influencing soil moisture through canopy interception and transpiration (Eagleson, 2002). Change of water balance can also have an effect on the vegetation cover. This interaction and feedback

between water balance and vegetation cover are difficult to diagnose and quantify, which therefore calls for the development and use of catchment ecohydrological models that couple hydrologic processes and vegetation dynamics.

\section{Appendix A}

\section{Variables and parameters in this paper}

$P(\bar{P})$

$R(\bar{R})$

E

$E_{0}$

$E_{0} / P$

$T(\bar{T})$

$F_{\mathrm{t}}\left(\bar{F}_{\mathrm{t}}\right)$

$F_{\mathrm{p}}\left(\bar{F}_{\mathrm{p}}\right)$

$F_{r}\left(\bar{F}_{r}\right)$

$R / P$

$E / P$

$R_{g}$

$R_{\mathrm{S}}$

$R_{g} / R$

$R_{\mathrm{S}} / R$

$k$

$a$

$\rho$

$F_{\mathrm{p}} / F_{\mathrm{t}}$

$F_{r} / F_{\mathrm{t}}$

$\Delta P_{i}$

$\Delta T_{i}$

$\Delta R_{i}$

$\varepsilon_{R}^{P}$
${ }_{P_{R}}^{P}, \ldots, \varepsilon_{R}^{P_{-n}}$

$\varepsilon_{R}^{T}$
Annual precipitation (long-term mean annual precipitation), $\mathrm{mm}$

Annual runoff (long-term mean annual runoff), $\mathrm{mm}$

Annual evapotranspiration, $\mathrm{mm}$

Annual potential evapotranspiration, $\mathrm{mm}$

Dryness index, ratio of mean annual potential evapotranspiration to precipitation

Annual temperature (long-term mean annual temperature), ${ }^{\circ} \mathrm{C}$

Annual recurrent fPAR (long-term mean annual recurrent fPAR)

Annual persistent fPAR (long-term mean annual persistent fPAR)

Annual total fPAR (long-term mean annual total fPAR)

Runoff coefficient, the ratio of annual runoff to precipitation

Evapotranspiration coefficient, ratio of annual evapotranspiration to precipitation

Annual subsurface runoff, mm

Annual surface runoff, $\mathrm{mm}$

The ratio of annual subsurface runoff to total runoff

The ratio of surface runoff to total runoff

The time step number

The single filter parameter in Eq. (1), the value is 0.925 for all catchments

The linear correlation coefficient

The proportion of woody vegetation

The proportion of non-woody vegetation

The annual departures from long-term mean annual values for precipitation The annual change in temperature compared to the long-term mean temperature

The annual departures from long-term mean annual values for total runoff Elasticity of total runoff to precipitation Elasticity of total runoff to previous precipitation Elasticity of total runoff to temperature 
$\Delta R_{\mathrm{s}, i}$

$\varepsilon_{R_{\mathrm{S}}}^{P}$

$\varepsilon_{R_{\mathrm{S}}}^{P_{-1}}, \ldots, \varepsilon_{R_{\mathrm{S}}}^{P_{-n}}$

$\varepsilon_{R_{\mathrm{s}}}^{T}$

$\Delta R_{g, i}$

$\varepsilon_{R_{g}}^{P}$

$\varepsilon_{R_{g}}^{P_{-1}}, \ldots, \varepsilon_{R_{g}}^{P_{-n}}$

$\varepsilon_{R_{g}}^{T}$

$R^{2}$

$F_{\text {test }}$

$\sigma^{2}$

$P_{\text {grow }}$

$T_{\text {grow }}$

$R_{\text {sd, grow }}$

$P_{\text {nongrow }}$

$\Delta F_{\mathrm{t}, i}$

$\varepsilon_{F_{\mathrm{t}}}^{P_{\text {grow }}}$

$\varepsilon_{F_{\mathrm{t}}}^{P_{\text {nongrow }}}$

$\varepsilon_{F_{\mathrm{t}}}^{T_{\text {grow }}}$

$\varepsilon_{F_{\mathrm{t}}}^{R_{\text {sd,grow }}}$

$\Delta F_{\mathrm{p}, i}$

$\varepsilon_{F_{\mathrm{p}}}^{P_{\text {grow }}}$

$\varepsilon_{F_{\mathrm{p}}}^{P_{\text {nongrow }}}$

$\varepsilon_{F_{\mathrm{p}}}^{T_{\text {grow }}}$

$\varepsilon_{F_{\mathrm{p}}}^{R_{\text {sd,grow }}}$
The annual departures from long-term mean annual values for surface runoff Elasticity of surface runoff to precipitation

Elasticity of surface runoff to previous precipitation

Elasticity of surface runoff to

temperature

The annual departures from long-term mean annual values for subsurface runoff

Elasticity of subsurface runoff to

precipitation

Elasticity of surface runoff to previous

precipitation

Elasticity of subsurface runoff to

temperature

The coefficient of determinant

The $F$ statistic

Error variance

Growing season precipitation

Growing season temperature

Growing season incoming shortwave radiation

Precipitation during non-growing season

The departures from long-term mean values for total fPAR

Elasticity of total fPAR to

precipitation during growing season

Elasticity of total fPAR to

precipitation during non-growing season

Elasticity of total fPAR to temperature during growing season

Elasticity of total fPAR to shortwave radiation during growing season

The departures from long-term mean values for persistent fPAR

Elasticity of persistent fPAR to precipitation during growing season

Elasticity of persistent fPAR to precipitation during non-growing season Elasticity of persistent fPAR to temperature during growing season Elasticity of persistent fPAR to shortwave radiation during growing season

The departures from long-term mean values for recurrent fPAR

$\begin{array}{cl}\varepsilon_{F_{\mathrm{r}}}^{P_{\text {grow }}} & \begin{array}{l}\text { Elasticity of recurrent fPAR to precipitation } \\ \text { during growing } \\ \text { season }\end{array} \\ \varepsilon_{F_{\mathrm{r}}}^{P_{\text {nongrow }}} & \begin{array}{l}\text { Elasticity of recurrent fPAR to precipitation } \\ \text { during non-growing }\end{array} \\ & \text { season } \\ \varepsilon_{F_{\mathrm{r}}} & \text { Elasticity of recurrent fPAR to temperature } \\ & \text { during growing } \\ & \text { season } \\ \varepsilon_{F_{\mathrm{r}}} & \text { Elasticity of recurrent fPAR to shortwave } \\ & \text { radiation during growing season }\end{array}$

Supplementary material related to this article is available online at: http://www.hydrol-earth-syst-sci.net/16/43/2012/ hess-16-43-2012-supplement.pdf.

Acknowledgements. The authors would like to thank the anonymous reviewers for their valuable comments and suggestions to improve the quality of the paper. We thank Randall J. Donohue for kindly providing most of the data used in this study. This paper was supported by the National Natural Science Foundation of China (NSFC Grant No. 51025931, 50939004) and by the United States National Science Foundation for the project "Water Cycle Dynamic in a Changing Environment: Advancing Hydrologic Science through Synthesis" (NSF Grant EAR-0636043, M. Sivapalan, PI). These supports are gratefully acknowledged.

Edited by: G. Blöschl

\section{References}

Arnell, N. W.: Global Warming, River Flows and Water Resources, Wiley, Chichester, 1996.

Arnold, J. G. and Allen, P. M.: Automated methods for estimating baseflow and ground water recharge from streamflow records, J. Am. Water Resour. Assoc., 35, 411-424, 1999.

Barnett, T. P., Adam, J. C., and Lettenmaier, D. P.: Potential impacts of a warming climate on water availability in snow-dominated regions, Nature, 438, 303-309, 2005.

Baudena, M., Boni, G., Ferraris, L., von Hardenberg, J., and Probenzale, A.: Vegetation response to rainfall intermittency in drylands: Results from a simple ecohydrological box model, Adv. Water Resour., 30, 1320-1328, 2007.

Berti, M. L., Bari, M. A., Charles, S. P., and Hauck, E. J.: Climate change, catchment runoff and risks to water supply in the southwest of Western Australia, Department of Environment, Western Australia, 2004

Brown, M. E., Pinzon, J. E., Didan, K., Morisette, J. T., and Tucker, C. J.: Evaluation of the consistency of long-term NDVI time series derived from AVHRR, SPOT-Vegetation, SeaWiFS, MODIS, and Landsat ETM+ sensors, IEEE T. Geosci. Remote, 44, $1787-$ 1793, 2006.

Budyko, M. I.: Climate and Life, Elsevier, New York, 1974. 
Caylor, K. K., Manfreda, S., and Rodriguez-Iturbe, I.: On the coupled geomorphological and ecohydrological organization of river basins, Adv. Water Resour., 28, 69-86, 2005.

Chiew, F. H. S.: Estimation of rainfall elasticity of streamflow in Australia, Hydrolog. Sci. J., 51, 613-625, 2006.

Churkina, G., Running, S. W., and Schloss, A. L.: Comparing global models of terrestrial net primary productivity (NPP): the importance of water availability, Global Change Biol., 5(Suppl. 1), 46-55, 1999.

Dai, A. G., Trenberth, K. E., and Qian, T. T.: A global dataset of Palmer Drought Severity Index for 1870-2002: relationship with soil moisture and effects of surface warming, J. Hydrometeorol., 5, 1117-1130, 2004.

Donohue, R. J., Roderick, M. L., and McVicar, T. R.: Deriving consistent long-term vegetation information from AVHRR reflectance data using a cover-triangle-based framework, Remote Sens. Environ., 112, 2938-2949, doi:10.1016/j.rse.2008.02.008, 2008.

Donohue, R. J., McVicar, T. R., and Roderick, M. L.: Climaterelated trends in Australian vegetation cover as inferred from satellite observations, 1981-2006, Global Change Biol., 15, 1025-1039, doi:10.1111/j.1365-2486.2008.01746.x, 2009.

Donohue, R. J., McVicar, T. R., and Roderick, M. L.: Assessing the ability of potential evaporation formulations to capture the dynamics in evaporative demand within a changing climate, J. Hydrol., 186-197, doi:10.1016/j.jhydrol.2010.03.020, 2010.

Dooge, J.: Sensitivity of runoff to climate change: A Hortonian approach, B. Am. Meteorol. Soc., 73, 2013, 1992.

Dooge, J., Bruen, M., and Parmentier, B.: A simple model for estimating the sensitivity of runoff to long-term changes in precipitation without a change in vegetation, Adv. Water Resour., 23, 153-163, 1999.

Eagleson, P. S.: Climate, soil, and vegetation: 1. Introduction to water balance dynamics, Water Resour. Res., 14, 705-712, doi:10.1029/WR014i005p00705, 1978.

Eagleson, P. S.: Ecohydrology: Darwinian expression of vegetation form and function, Cambridge University Press, 170-207, 2002.

Eckhardt, K.: How to construct recursive digital filters for baseflow separation, Hydrol. Process., 19, 507-515, 2005.

FAO: Report on the agro-ecological zones project, Rome, 1978.

Gallo, K., Ji, L., Reed, B., Dwyer, J., and Eidenshink, J.: Comparison of MODIS and AVHRR 16-day Normalized Difference Vegetation Index composite data, Geophys. Res. Lett., 31, L07502, doi:10.1029/2003GL019385, 2004.

Gallo, K., Ji, L., Reed, B., Eidenshink, J., and Dwyer, J.: Multiplatform comparisons of MODIS and AVHRR Normalized Difference Vegetation Index data, Remote Sens. Environ., 99, 221$231,2005$.

Gill, T. K., Phinn, S. R. Armston, J. D., and Pailthorpe, B. A.: Estimating tree-cover change in Australia: challenges of using the MODIS vegetation index product, Int. J. Remote Sens., 30, 1547-1565, doi:10.1080/01431160802509066, 2009.

Grau, H. R. and Veblen, T. T.: Rainfall variability, fire and vegetation dynamics in neotropical montane ecosystems in northwestern Argentina, J. Biogeogr., 27, 1107-1121, 2000.

Harman, C. J., Troch, P. A., and Sivapalan, M.: Functional model of water balance variability at the catchment scale: 2 . Elasticity of fast and slow runoff components to precipitation change in the continental United States, Water Resour. Res., 47, W02523,
doi:10.1029/2010WR009656, 2011.

Horton, R. E.: The role of infiltration in the hydrologic cycle, Trans. Am. Geophys. Union, 14, 446-460, 1933.

Huxman, T., Smith, M., Fay, P., Knapp, A., Shaw, M., Loik, M., Smith, S., Tissue, D., Zak, J., Weltzin, J., Pockman, W., Sala, O., Haddad, B., Harte, J., Koch, G., Schwinning, S., Small, E., and Williams, D.: Convergence across biomes to a common rainuse efficiency, Nature, 429, 651-654, doi:10.1038/nature02561, 2004.

Jones, D. A., Wang, W., and Fawcett, R.: High-quality spatial climate data sets for Australia, Aust. Meteorol. Oceanogr. J., 58, 233-248, 2009.

Jones, R. N., Chiew, F. H. S., Boughton, W. C., and Zhang, L.: Estimating the sensitivity of mean annual runoff to climate change using selected hydrological models, Adv. Water Resour., 29, 1419-1429, 2005.

Kahn, L. P., Earl, J. M., and Nicholls, M.: Planning as a tool to improve production and function of grasslands in the mid-north of South Australia, Proceedings of the Stipa Conference, Burra, South Australia, 2005.

Kitsios, A., Bari, M. A., and Charles, S. P.: Projected impacts of climate change on the Serpentine catchment - Downscaling from multiple general circulation models, Department of Water, Western Australia, 2008.

Knapp, A. K. and Smith, M. D.: Variation among biomass in temporal dynamics of aboveground net primary production, Science, 291, 481-484, 2001.

Kochendorfer, J. P. and Ramírez, J. A.: Modeling the monthly mean soil-water balance with a statistical-dynamical ecohydrology model as coupled to a two-component canopy model, Hydrol. Earth Syst. Sci., 14, 2099-2120, doi:10.5194/hess-14-20992010, 2010.

Lyne, V. and Hollick, M.: Stochastic time-variable rainfall-runoff modelling, in: Proc. Hydrology and Water Resources Symposium, Perth, Inst. of Engrs. Australia, 89-92, 1979.

Ma, H., Yang, D., Tan, S. K., Gao, B., and Hu, Q.: Impact of climate variability and human activity on streamflow decrease in the Miyun Reservoir catchment, J. Hydrol., 389, 317-324, 2010.

McQueen, A. E.: Australia: physical and social geography, in: The Far East and Australasia 2003, 34th Edn., London and New York, Europa, 2002.

Merz, A., Alewell, C., Hiltbrunner, E., and Banninger, D.: Plantcompositional effects on surface runoff and sediment yield in subalpine grassland, J. Plant Nutr. Soil Sci., 172, 777-788, doi:10.1002/jpln.200800231, 2009.

Milly, P. C. D.: Climate, soil water storage, and the average annual water balance, Water Resour. Res., 30, 2143-2156, doi:10.1029/94WR00586, 1994.

Milly, P. C. D., Wetherald, R. T., Dunne, K. A., and Delworth, T. L.: Increasing risk of great floods in a changing climate, Nature, 415, 514-517, 2002.

Nemani, R. R., Keeling, C. D., Hashimoto, H., Jolly, W. M., Piper, S. C., Tucker, C. J., Myneni, R. B., and Running, S. W.: Climatedriven increases in global terrestrial net primary production from 1982 to 1999, Science, 300, 1560-1563, 2003.

Ni, J., Harrison, S. P., Prentice, I. C., and Kutzbach, J. E.: Impact of climate variability on present and Holocene vegetation: a modelbased study, Ecol. Model., 191, 469-486, 2006. 
Notaro, M.: Response of the mean global vegetation distribution to interannual climate variability, Clim. Dynam., 30, 845-854, doi:10.1007/s00382-007-0329-7, 2008.

Peel, M. C., Chiew, F. H. S., Western, A. W., and McMahon, T. A.: Extension of Unimpaired Monthly Streamflow Data and Regionalisation of Parameter Values to Estimate Streamflow in Ungauged Catchments, National Land and Water Resources Audit, Canberra, 2000.

Ponce, V. M. and Shetty, A. V.: A conceptual model of catchment water balance: 1. Formulation and calibration, J. Hydrol., 173, 27-40, 1995a.

Ponce, V. M. and Shetty, A. V.: A conceptual model of catchment water balance: 2. Application to runoff and baseflow modeling, J. Hydrol., 173, 41-50, 1995b.

Revelle, R. R. and Waggoner, P. E.: Effects of a carbon dioxideinduced climatic change on water supplies in the western United States, in: Changing Climate, Nat. Acad., Washington, DC, 419432, 1983.

Rosenzweig, M. L.: Net primary productivity of terrestrial communities: prediction from climatological data, Am. Nat., 102, 67-74, 1968.

Sankaran, M., Hanan, N. P., Scholes, R. J., Ratnam, J., Augustine, D. J., Cade, B. S., Gignoux, J., Higgins, S. I., Le Roux, X., Ludwig, F., Ardo, J., Banyikwa, F., Bronn, A., Bucini, G., Caylor, K. K., Coughenour, M. B., Diouf, A., Ekaya, W., Feral, C. J., February, E. C., Frost, P. G., Hiernaux, P., Hrabar, H., Metzger, K. L., Prins, H. H., Ringrose, S., Sea, W., Tews, J., Worden, J., and Zambatis, N.: Determinants of woody cover in African Savannas, 2005, Nature, 438, 846-849, 2005.

Sankarasubramanian, A., Vogel, R. M., and Limbrunner, J. F.: Climate elasticity of streamflow in the United States, Water Resour. Res., 37, 1771-1781, 2001.

Scanlon, T. M., Caylor, K. K., Manfreda, S., Levin, S. A., and Rodriguez-Iturbe, I.: Dynamic response of grass cover to rainfall variability: implications for the function and persistence of savanna ecosystems, Adv. Water. Resour., 28, 291-302, 2005.

Schaake, J. C.: From Climate to Flow in Climate Change and US Water Resources, edited by: Waggoner, P. E., Chapter 8, John Wiley, New York, 77-206, 1990..

Schlesinger, W. H.: Biogeochemistry: an analysis of global change, 2nd Edn., Academic, San Diego, 1997.
Scott, R. L., Huxman, T. E., Williams, D. G., and Goodrich, D. C.: Ecohydrological impacts of woody-plant encroachment: seasonal patterns of water and carbon dioxide exchange within a semiarid riparian environment, Global Change Biol., 12, 311324, 2006.

Smith, K., Boniecka, L., Bari, M. A., and Charles, S. P.: The impact of climate change on rainfall and streamflow in the Denmark River catchment, Western Australia, Department of Water, Division of Water Resources Management, Surface water hydrology series no. HY 30, 2009.

Stephenson, N. L.: Climatic control of vegetation distribution: the role of the water balance, Am. Nat. 135, 649-670, 1990.

Troch, P. A., Martinez, G. F., Pauwels, V. R. N., Durcik, M., Sivapalan, M., Harman, C. J., Brooks, P. D., Gupta, H. V., and Huxman, T. E.: Climate and vegetation water-use efficiency at catchment scales, Hydrol. Process., 23, 2409-2414, doi:10.1002/hyp.7358, 2009.

Tucker, C. J., Pinzon, J. E., Brown, M. E., Slayback, D. A., Pak, E. W., Mahoney, R., Vermote, E. F., and El Saleous, N.: An extended AVHRR 8-km NDVI dataset compatible with MODIS and SPOT vegetation NDVI data, Int. J. Remote Sens., 26, 44854498, 2005.

Vogel, R. M., Wilson, I., and Daly, C.: Regional regression models of annual streamflow for the United States, J. Irrig. Drain. Eng., 125, 148-157, 1999.

Williams, C. A. and Albertson, J. D.: Dynamical effects of the statistical structure of annual rainfall on dryland vegetation, Global Change Biol., 12, 777-792, 2006.

Yang, D., Sun, F., Liu, Z., Cong, Z., and Lei, Z.: Interpreting the complementary relationship in non-humid environments based on the Budyko and Penman hypotheses, Geophys. Res. Lett., 33, L18402, doi:10.1029/2006GL027657, 2006.

Yang, D., Shao, W., Yeh, P., Yang, H., Kanae, S., and Oki, T.: Impact of Vegetation Coverage on Regional Water Balance in the Non-humid Regions of China, Water Resour. Res., 45, W00A14, doi:10.1029/2008WR006948, 2009.

Yokoo, Y., Sivapalan, M., and Oki, T.: Investigating the roles of climate seasonality and landscape characteristics on mean annual and monthly water balances, J. Hydrol., 357, 255-269, 2006. 